\title{
32 Long-term care and reciprocity: does helping with grandchildren result in the receipt of more help at older ages?
}

- In four out of ten households, older adults provide help to their grandchildren

- Caring for grandchildren increases the likelihood to receive help from adult children later in life

- Substantial in-kind transfer of care services between generations is likely to benefit welfare state budget

\subsection{Why do adult children care for older parents?}

In the last century, European countries experienced a spectacular demographic transition. A sharp decline in fertility rates was paired with a steady decrease in mortality. This dual dynamic has progressively increased the proportion of people aged 65 and over, to the point that recent projections estimate they will comprise more than 30 per cent of the population by 2050 (Eurostat 2008). One consequence of an ageing population is an increase in the need by older people for care services, due to the limitations that they may experience in performing daily activities (i.e. basic tasks such as personal care, moving around the house and so on). Family members, and in particular adult children, are the ones who most frequently provide the bulk of care for older adults (see e.g. Kalwij et al. 2012, for recent evidence based on SHARE data).

Understanding the determinants of care provision by adult children is of paramount importance from a public policy point of view. It has been claimed that informal care from children reduces the probability of nursing home entry (Charles \& Sevak 2005). Others see the care supplied by adult children as a net substitute for publicly provided home care (van Houtven \& Norton 2004, Bonsang 2009). As such, informal care provision might decrease the fiscal cost of public long-term care expenditure programmes. At the same time, however, the provision of long-term care by adult children can have a negative impact on their labour market participation and career prospects, especially for women (Pezzin et al. 1999, Bolin et al. 2008). 
Why do adult children care for older parents? They might do so out of pure altruism or rather because they are, or expect to be, compensated by their parents. This latter type of motivation has been discussed in the literature on exchange motives for bequest, as for example in early works by Bernheim et al. (1985) and Cox (1987). More recently, using SHARE data, Alessie et al. (2011) have shown that both altruism and exchange motives matter for long term care provision and inter-vivos financial transfers.

Within family in-kind transfers are not limited to informal care provided by adult children to their parents. Older individuals quite often engage in grandchildren care, thus alleviating the burden of family duties on their adult children, especially their daughters. Childcare is a time consuming activity, and despite the spectacular improvement of labour market performance of women in the last century, still leads mothers to experience lower labour market involvement and worse career prospect than desired. Public supply of such a care service is heterogeneous both across European countries and within each country (childcare facilities' provision is often part of regional or even municipal duties), and often it does not satisfy households' needs. Blau and Currie (2006), among others, underlined that help from older parents as grandchildren care providers can contribute to reduce the gender gap in labour market outcomes associated with fertility decisions. Such a within-family source of childcare is likely to expand in the near future, because a larger fraction of older people are now in relatively good health and, as a result, more of them are able to provide grandparental childcare (Mackenbach et al. 2008, present a comprehensive survey on the topic). While a high proportion of grandparental childcare is observed throughout Europe, the intensity of provision varies across countries, with Mediterranean countries displaying higher frequency rates than Continental and Nordic countries (Albertini et al. 2007, Hank \& Buber 2009).

In this chapter we investigate whether parents who have provided help by taking care of their grandchildren receive more informal care from their children when they experience the onset of limitations in performing activities of daily living. Such an association may be the result of reciprocal altruism, a concept often labelled in evolutionary psychology and experimental economics as "delayed reciprocity" (see e.g. Neo et al. 2013), or it may be a "repayment" for previous informal care received. From a behavioural point of view the difference is that delayed reciprocity does not require parents and children to agree upon the exchange beforehand: children react to an "act of kindness" received from the parent with an altruistic behaviour later in life when their parents are in need. In comparison, an exchange motive does not require altruism in individual behaviour, but an implicit or explicit "contract” taking place between parents and children over time.

From a policy perspective, whether high involvement in long term care by adult children is the result of delayed reciprocity or whether it is part of an 
exchange agreement has a relevant role. In the former case, children are not likely to respond to economic incentives to change their caring and labour market patterns. If, on the other hand, informal care by adult children is the result of exchange considerations, economic incentives might be effective. From a life cycle perspective, the combination of informal grandchild care and long-term care provision might decrease the overall fiscal cost of public care expenditure programmes. Moreover, such savings may be attained without jeopardising the daughters' early career and labour market prospects.

\subsection{Grandparent childcare as a determinant of informal long term care provision}

We used data from Waves 1, 2 and 4 of SHARE. The key idea was to investigate whether the provision of informal childcare by grandparents, as observed in the first two waves of data collection (in 2004 and 2006) was significantly related to the prevalence (probability of receiving care) and the intensity (number of days of care received) of informal long term care provided by adult children living outside the household at the time of Wave 4 (in 2011). In order to achieve our purpose, it was necessary to limit the sample to respondents who participated in Wave 4 and in at least one earlier wave of data collection (Wave 1 and/or Wave 2). In constructing the dataset, our first target was to link the information regarding the grandchild care that respondents' adult children received from their parents in the earlier waves to the information about the help that adult children supplied to their parents in Wave 4 (to the respondent, to his or her spouse, or both). While the information about grandchildren assistance is individual (both respondent and spouse/partner individually answer the related questions), the data on the care received from children regards the overall family (both respondent and spouse). For this reason we combined the relevant information in such a way as to get one record per household. This operation reduced the dimension of our database, but made the variables on help given and help received comparable. Finally, we focused exclusively on those respondents that resided as a couple or alone in all the three waves considered. That is, we did not include respondents who had lived in extended family households at any time. We also excluded respondents who had been in receipt of personal help from their children already in Waves 1 or 2 .

Tables 32.1 and 32.3 show the ratios of respondents' households that gave help to their children and received help from them, respectively. Tables 32.2 and 32.4 display the mean frequency of such help, expressed as total days per month of help (the sum of days of help provided by each parent in the household). We can 
observe that while the prevalence of giving help to grandchildren or receiving help from children is similar in all European countries, the mean frequency of care is higher in Mediterranean countries and Poland with respect to Nordic or Central European countries (even if these differences are not statistically significant).

Table 32.1: Help given with grandchildren care

\begin{tabular}{lllllc}
\hline Country & Min & Max & Mean & Std. Dev. & Nr obs \\
\hline Austria & 0 & 1 & 0.354 & 0.479 & 268 \\
Germany & 0 & 1 & 0.372 & 0.484 & 522 \\
Sweden & 0 & 1 & 0.494 & 0.500 & 765 \\
Netherlands & 0 & 1 & 0.478 & 0.500 & 709 \\
Spain & 0 & 1 & 0.422 & 0.495 & 287 \\
Italy & 0 & 1 & 0.454 & 0.498 & 456 \\
France & 0 & 1 & 0.416 & 0.493 & 847 \\
Denmark & 0 & 1 & 0.442 & 0.497 & 781 \\
Switzerland & 0 & 1 & 0.325 & 0.469 & 530 \\
Belgium & 0 & 1 & 0.462 & 0.499 & 769 \\
Czech Republic & 0 & 1 & 0.349 & 0.477 & 447 \\
Poland & 0 & 1 & 0.393 & 0.489 & 346 \\
\hline Total & 0 & 1 & 0.424 & 0.494 & 6,727 \\
\hline
\end{tabular}

Source: SHARE Wave 1 release 2.5.0, Wave 2 release 2.5.0, Wave 4 release 1

Table 32.2: Total days of help to grandchildren conditional on giving help

\begin{tabular}{lllrrr}
\hline Country & Min & Max & \multicolumn{1}{c}{ Mean } & Std. Dev. & Nr obs \\
\hline Austria & 0.5 & 30 & 9.795 & 11.593 & 95 \\
Germany & 0.5 & 30 & 8.812 & 10.758 & 194 \\
Sweden & 0 & 30 & 4.290 & 6.598 & 378 \\
Netherlands & 0.5 & 30 & 5.080 & 5.728 & 339 \\
Spain & 0.5 & 30 & 16.087 & 13.245 & 121 \\
Italy & 0.5 & 30 & 19.041 & 13.073 & 207 \\
France & 0 & 30 & 6.173 & 8.975 & 352 \\
Denmark & 0 & 30 & 3.730 & 5.315 & 345 \\
Switzerland & 0 & 30 & 5.180 & 6.562 & 172 \\
Belgium & 0 & 30 & 10.620 & 11.335 & 355 \\
Czech Republic & 0 & 30 & 6.917 & 9.634 & 156 \\
Poland & 0 & 30 & 13.886 & 13.310 & 136 \\
\hline Total & 0 & 30 & 8.056 & 10.359 & 2,850 \\
\hline
\end{tabular}

Source: SHARE Wave 1 release 2.5.0, Wave 2 release 2.5.0, Wave 4 release 1 
Table 32.3: Help received from children in Wave 4

\begin{tabular}{lllllc}
\hline Country & Min & Max & Mean & Std. Dev. & Nr obs \\
\hline Austria & 0 & 1 & 0.086 & 0.281 & 268 \\
Germany & 0 & 1 & 0.082 & 0.275 & 522 \\
Sweden & 0 & 1 & 0.071 & 0.256 & 765 \\
Netherlands & 0 & 1 & 0.035 & 0.185 & 709 \\
Spain & 0 & 1 & 0.087 & 0.282 & 287 \\
Italy & 0 & 1 & 0.064 & 0.244 & 456 \\
France & 0 & 1 & 0.053 & 0.224 & 847 \\
Denmark & 0 & 1 & 0.092 & 0.289 & 781 \\
Switzerland & 0 & 1 & 0.040 & 0.195 & 530 \\
Belgium & 0 & 1 & 0.057 & 0.232 & 769 \\
Czech Republic & 0 & 1 & 0.183 & 0.387 & 447 \\
Poland & 0 & 1 & 0.087 & 0.282 & 346 \\
\hline Total & 0 & 1 & 0.073 & 0.261 & 6,727 \\
\hline
\end{tabular}

Source: SHARE Wave 1 release 2.5.0, Wave 2 release 2.5.0, Wave 4 release 1

Table 32.4: Days of help received from children living outside the household given that help was received

\begin{tabular}{lllrrc}
\hline Country & Min & Max & Mean & Std. Dev. & Nr obs \\
\hline Austria & 0.5 & 30 & 8.261 & 10.388 & 23 \\
Germany & 0.5 & 30 & 4.384 & 7.461 & 43 \\
Sweden & 0.5 & 30 & 4.352 & 6.835 & 54 \\
Netherlands & 0.5 & 30 & 4.760 & 7.991 & 25 \\
Spain & 0.5 & 30 & 17.160 & 13.806 & 25 \\
Italy & 0.5 & 30 & 18.845 & 12.836 & 29 \\
France & 0.5 & 30 & 4.367 & 7.378 & 45 \\
Denmark & 0.5 & 30 & 4.639 & 8.660 & 72 \\
Switzerland & 0.5 & 30 & 7.619 & 11.291 & 21 \\
Belgium & 0.5 & 30 & 11.295 & 12.442 & 44 \\
Czech Republic & 0.5 & 30 & 9.634 & 11.566 & 82 \\
Poland & 0.5 & 30 & 16.233 & 13.368 & 30 \\
\hline Total & 0.5 & 30 & 8.463 & 11.221 & 493 \\
\hline
\end{tabular}

Source: SHARE Wave 1 release 2.5.0, Wave 2 release 2.5.0, Wave 4 release 1 
As it is the standard in the long term care economic literature, we ran a two part model. We examined both the probability of receiving informal care from children, and the number of days of care conditional on receiving help. Therefore, the first part of the model was a probit regression in which the dependent variable was a dummy that took value one if any of the respondent's adult children gave help in Wave 4 to the respondent or to his/her spouse. The second part of the analysis was a linear regression run on the subsample of those who received help from their children. The regressand in that analysis was the total number of days per month in which parents received care from at least one adult child living outside the household. The key regressor in both cases was a dummy variable that took value one if the respondent or spouse provided help to grandchildren in Wave 1 or Wave 2. We then controlled for a full set of informal care determinants: a quadratic in age (mean age for couples), whether a given observation represented a single or a couple household, the maximum level of limitations in activities of daily living (ADL) among the parents in Wave 4, the maximum variation in the ADL status between Wave 1 or 2 and Wave 4, the household income and the number of sons and daughters separately. We also included a full set of country dummies to account for heterogeneity in institutions and in cultural traits that may affect caregiving decisions.

As a control for robustness we considered a set of variables that describe the type of family from a "caring" perspective. For this purpose, we used three variables that are available in the "drop-off" SHARE questionnaire, combining them in a "care" coefficient through a summative rating scale. On these items, respondents were asked to express their attitude (agreement or disagreement on a scale from one to five) towards the following statements: i) “Grandparents' duty is to contribute towards the economic security of grandchildren and their families" ii) Grandparents' duty is to help grandchildren's parents in looking after young grandchildren and iii) the family should provide "help with household chores for older persons who are in need such as help with cleaning, washing”. It is important to specify that lower scores in the caring variables and hence lower values of the care index stand for stronger family solidarity. Table 32.5 reports the mean and the standard deviation of the "caring" index. As we expected Mediterranean countries are characterised by stronger family values than Central and Northern European countries.

We did not include this "caring family" control in the baseline specification of the two part model, since the relevant questions are part of the drop-off questionnaire which was subject to a higher non-response rate than the main questionnaire. 
Table 32.5: Care index by country

\begin{tabular}{llllll}
\hline Country & Min & Max & Mean & Std. Dev. & Nr obs \\
\hline Austria & 1 & 4.857 & 2.790 & 0.735 & 243 \\
Germany & 1 & 4.571 & 2.632 & 0.594 & 340 \\
Sweden & 1 & 5 & 2.801 & 0.757 & 530 \\
Netherlands & 1 & 5 & 3.077 & 0.611 & 492 \\
Spain & 1 & 3.857 & 2.363 & 0.637 & 157 \\
Italy & 1 & 4.143 & 2.281 & 0.608 & 291 \\
France & 1,286 & 4.286 & 2.548 & 0.585 & 455 \\
Denmark & 1 & 5 & 3.195 & 0.641 & 339 \\
Switzerland & 1 & 5 & 2.756 & 0.682 & 477 \\
Belgium & 1 & 5 & 2.750 & 0.744 & 542 \\
Czech Republic & 1,286 & 4.571 & 2.905 & 0.583 & 287 \\
Poland & 1 & 4 & 2.333 & 0.618 & 221 \\
\hline Total & 1 & 5 & 2.744 & 0.706 & 4,374 \\
\hline
\end{tabular}

Source: SHARE Wave 1 release 2.5.0, Wave 2 release 2.5.0, Wave 4 release 1

\subsection{Reciprocity within European families}

Table 32.6 reports the results from the two part model in its baseline specification (first two columns), and with the "caring family" index as an additional control (last two columns). Columns corresponding to the probit regressions report marginal effects. As the table shows, having had previously provided childcare to the grandchildren was highly significant and points to an increase of 15.3 per cent in the probability of receiving informal care by adult children. This value increased to 19.4 per cent when we controlled for the "caring attitude" of the family (column 3). Care needs (measured by the number of ADL limitations) were an important driver both of the probability and of the amount of care received (even if the latter was not precisely estimated when caring attitude was included). However, the extent of changes in ADL functioning between the waves seems to have been less important.

Couples were significantly less likely to have received care from adult children living elsewhere than singles: the 44.8 per cent to 53.4 per cent decline in the probability of adult children providing care to a couple household suggests that the cohabiting partner plays a major role as informal care provider, or that married couples are healthier. While the income coefficient was not significant, the probability of care provision as well as the amount of care received were higher the older the care recipient was. Also, the greater the number of children, the more 
likely it was to have received care from them. In the baseline specification having one extra daughter increased the chances of receiving care from children by 15.6 per cent, while one extra son induced a 13.9 per cent increase. These figures rose to around 17 per cent and the difference between the two diminished when we controlled for the caring attitude, even though the difference between the marginal effects was not significant in the baseline or in the extended specification.

Table 32.6: Two part model

\begin{tabular}{|c|c|c|c|c|}
\hline \multirow[b]{3}{*}{ Variable } & \multicolumn{4}{|c|}{ CARE PROVISON BY ADULT CHILDREN } \\
\hline & \multicolumn{2}{|l|}{ Baseline } & \multicolumn{2}{|l|}{ Caring family } \\
\hline & $\begin{array}{l}\text { Probability } \\
\text { (Probit) } \\
\text { (1) }\end{array}$ & $\begin{array}{l}\text { Extent } \\
\text { (OLS) } \\
(2)\end{array}$ & $\begin{array}{l}\text { Probability } \\
\text { (Probit) } \\
\text { (3) }\end{array}$ & $\begin{array}{l}\text { Extent } \\
\text { (OLS) } \\
(4)\end{array}$ \\
\hline Care for grandchildren in w1 or w2 & $0.153^{\star \star \star}$ & -0.203 & $0.194^{\star \star \star}$ & 1.767 \\
\hline Log income & 0.022 & -0.81 & -0.035 & -1.351 \\
\hline ADL_w4 & $0.134^{\star \star \star \star}$ & $1.164^{\star \star}$ & $0.171^{\star \star \star \star}$ & 0.92 \\
\hline Delta_adl (increase in ADL-dummy) & $0.214^{\star \star}$ & -1.542 & 0.144 & 0.666 \\
\hline Couple household & $-0.448^{\star \star \star \star}$ & -0.656 & $-0.534^{\star \star \star \star}$ & -0.891 \\
\hline No. of male children & $0.139^{\star \star \star \star \star}$ & 0.129 & $0.172^{\star \star \star \star}$ & 0.215 \\
\hline No. of female children & $0.156^{\star \star \star \star}$ & 0.43 & $0.170^{\star \star \star \star}$ & 0.755 \\
\hline Mean age & 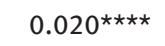 & $0.136 * \star \star$ & $0.022^{\star \star \star \star}$ & $0.169^{\star \star}$ \\
\hline Mean age squared & $0.000^{\star \star \star \star}$ & $0.000^{\star \star \star}$ & $0.000^{\star \star \star \star}$ & $0.000^{\star \star}$ \\
\hline Care coefficient & & & -0.062 & 0.405 \\
\hline Austria & -0.12 & 3.126 & 0.019 & 2.372 \\
\hline Sweden & $-0.238^{\star \star}$ & -0.594 & -0.113 & -2.312 \\
\hline Netherlands & $-0.525^{\star \star \star \star}$ & 0.252 & $-0.562^{\star \star \star}$ & 1.006 \\
\hline Spain & -0.289 & $8.463^{\star \star \star}$ & -0.143 & $7.703^{\star \star}$ \\
\hline Italy & $-0.284^{\star \star}$ & $12.669^{\star \star \star \star}$ & -0.146 & $9.415^{\star \star \star}$ \\
\hline France & $-0.396^{\star \star \star \star}$ & -0.877 & $-0.310^{\star \star}$ & -1.72 \\
\hline Denmark & 0.022 & 0.146 & -0.065 & -1.559 \\
\hline Switzerland & 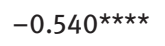 & 2.013 & $-0.424^{\star \star \star}$ & 0.193 \\
\hline Belgium & 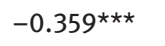 & $5.781^{\star \star \star}$ & -0.267 & 3.194 \\
\hline Poland & -0.247 & $15.309^{\star \star \star \star}$ & 0.227 & $15.082^{\star \star \star}$ \\
\hline Czech Republic & $0.492^{\star \star \star \star}$ & $4.398^{\star \star}$ & $0.497^{\star \star \star \star}$ & 3.156 \\
\hline Intercept & $-2.913^{\star \star \star \star \star ~}$ & -3.241 & $-2.064^{\star \star}$ & -3.207 \\
\hline$N$ & 6,521 & 490 & 4,254 & 311 \\
\hline
\end{tabular}

Significance: ${ }^{* *}=5 \% ;{ }^{* * *}=1 \% ; * \star * *=0.1 \%$

Notes: Germany is the excluded country. The regression also includes a dummy which takes value one for families observed in Waves 2 and 4, and zero for those observed in Waves 1 and 4. Source: SHARE Wave 1 release 2.5.0, Wave 2 release 2.5.0, Wave 4 release 1 
As noted earlier in this chapter, provision of childcare by grandparents and subsequent parent care receipt might be shaped by a positive cultural attitude toward caring for family members. If this were the case, despite the different timing of grandchildren and elder care, the significant parameters of interest could not be given a causal interpretation. We attempted to capture part of the difference in the cultural attitudes towards long term care by including in the analysis a set of country dummies. However, the country variables did not exhibit a clear pattern that may be easily interpreted. As we already explained, we went further into this issue by including the caring family index in the two part model proposed in columns (3) and (4). This additional control did not change the broad picture of the analysis, that is, caring for grandchildren early in life still positively affected the probability of receiving care. If anything, the effect seems stronger in column (3) compared to column (1). The caring family index per se was not found to be significant. The same was true also for the single items included in the index when they were used directly in the regression (the results of these regressions are not reported).

\subsection{Importance of in-kind care transfers within families}

In this chapter we exploited the longitudinal dimension of SHARE data to investigate the presence and intensity of reciprocity in informal care provision in eleven European countries, including Mediterranean, Continental and Nordic countries. We estimated a two part model to analyse both the propensity to provide care and the amount of care provided by children. The results consistently show that previously provided grandparental childcare results in a higher probability that adult children will later reciprocate providing informal care to their older parents, but does not affect the extent of informal care provision to the same degree.

Understanding the dynamics of reciprocity in the provision of informal care among families represents a timely and highly relevant policy issue. Active childcare provision by grandparents might reduce the cost of raising children and, in turn, both influence the fertility decisions of young adults and foster their labour market participation. Previous informal care provision by active grandparents seems to result later in a reciprocated provision of informal care by the adult children, once their older parent experience the onset of care needs. Such an informal delayed transfer of in-kind services is likely to reduce the burden on welfare state budgets. 


\section{References}

Albertini, Marco, Kohli, Martin, Vogel, Claudia (2007): “Intergenerational transfers of time and money in European families: common patterns - different regimes?”. In: Journal of European Social Policy 17(4), p. 319-334.

Alessie, Rob, Angelini, Viola, Pasini, Giacomo (2011): "Is it true love? Altruism versus exchange in time and money transfers", W.P Venice Econonomics department 27/2011.

Bernheim, Douglas, Shleifer, Andrei, Summers, Lawrence (1985): “The strategic bequest motive". In: Journal of Political Economy 93 (6), p. 1045-1076.

Blau, David, Currie, Janet (2006): “Preschool, day care, and after school care: who's minding the kids?". In: Hanushek, Eric, Welch, Finis (Eds.): Handbook on the economics of education, Vol. 2, Chapter 20. Amsterdam, North Holland Press.

Bolin, Kristian, Lindgren, Bjorn, Lundborg. Petter (2008): "Your next of kin or your own career? Caring and working among the 50+ of Europe". In: Journal of Health Economics 27, p. 718-738.

Bonsang, Eric (2009): "Does informal care from children to their elderly parents substitute for formal care in Europe?”. In: Journal of Health Economics 28(1), p. 143-154.

Charles, Kerwin, Sevak, Purvi (2005): “Can family caregiving substitute for nursing home care?”. In: Journal of Health Economics 24, p. 1174-1190.

Comas-Herrera, Adelina, Wittenberg, Raphael, Costa-Font, Joan, Gori, Cristiano, Di Maio, Alessandra, Patxot, Concepcio, Pickard, Linda, Pozzi, Alessandro, Rothgang, Heinz (2006): "Future long-term care expenditure in Germany, Spain, Italy and the United States". In: Ageing \& Society 26, p. 285-302.

Cox, Donald (1987): “Motives for private income transfers”. In: Journal of Political Economy 95 (3), p. 508-546.

Eurostat (2008): Europe in figure - Eurostat Yearbook 2008.

Hank, Karsten, Buber, Isabella (2009): "Grandparents caring for their grandchildren: findings from the 2004 Survey of Health, Ageing and Retirement in Europe". In: Journal of Family Issues 30(1), p. 53-73.

van Houtven, Courtney, Norton, Edward ( 2004): “Informal care and health care use of older adults”. In: Journal of Health Economics 23, p. 1159-1180.

Kalwij, Adriaan, Pasini, Giacomo, Wu, Minggin (2012): “Homecare for the elderly: family, friends and the state". In: Review of Economics of the Household, forthcoming.

Mackenbach, Johan, Nusselder, Wilma, Polinder, Suzanne, Kunst, Anton (2008): “Compression of morbidity: a promising approach to alleviate the societal consequences of population aging?", NETSPAR Panel Paper 7, p. 9-48.

Neo, Wei Siong, Yu, Michael, Weber, Roberto, Gonzalez, Cleotilde (2013): “The effects of time delay in reciprocity games”. In: Journal of Economic Psychology 34(1), p. 20-35.

Pezzin, Liliana, Steinberg Schone, Barbara (1999): “Intergenerational household formation, female labor supply and informal caregiving: a bargaining approach”. In: Journal of Human Resources 34(3), p. 475-503. 